\title{
PELATIHAN BUDIDAYA KAKTUS MINI \\ BAGI IBU-IBU ANGGOTA PKK BANJAR KERTHABUANA KAJA DENPASAR UTARA
}

\author{
Rindang Dwiyani ${ }^{1}$, Hestin Yuswanti ${ }^{2}$, I Nyoman Gede Astawa ${ }^{3}$, Ni Nyoman Ari Mayadewi ${ }^{4}$
}

\begin{abstract}
ABSTRAK
Kaktus mini merupakan tanaman indoor penghias ruangan yang memiliki prospek baik untuk dikembangkan. Budidayanya yang sangat mudah tidak banyak diketahui orang sehingga perlu menyebarkan ilmu budidaya ini kepada masyarakat, khususnya kaum ibu rumah tangga. Ibu rumah tangga menghabiskan sebagian besar waktunya di rumah untuk mengurus keluarga, namun pemanfaatan waktu yang tersisa perlu dipikirkan dengan baik agar tidak terbuang percuma. Pelatihan budidaya kaktus mini untuk para ibu anggota PKK di Banjar Kerthabuwana Kaja ini telah dilaksanakan dengan baik. Kegiatan ini memberikan pengetahuan serta ketrampilan kepada para ibu sehingga mereka dapat melakukannya di rumah sebagai bagian dari hobi sekaligus mendatangkan uang. Metode yang digunakan adalah metode ceramah dan praktik langsung. Tujuan dari kegiatan ini adalah meningkatkan ketrampilan para ibu rumah tangga dalam budidaya tanaman kaktus mini. Output dari kegiatan ini adalah ketrampilan sederhana yang didapat oleh para ibu rumah tangga, yakni pembiakan kaktus mini hingga pemeliharaannya sampai siap dijual.
\end{abstract}

Kata kunci: kaktus mini, budidaya, ibu PKK

\begin{abstract}
Mini cactus is an indoor ornamental plant. The cultivation is relatively easy; however, not many people are familiar with the method. Housewives spend most of their time at home to take care of their families, but the use of the remaining time needs to be well managed. The current community service on cultivation method of mini cacti plants offered to the housewives especially for them who are still productive-age. The Training has been carried out at 16 July 2018 at Banjar Kerthabuwana Kaja, Northern of Denpasar. The objective is to provide knowledge and skills on the cultivation of mini cacti plants for those of housewives. Lecturing and practices were used to share the knowledge. The output of this activity is a simple skill in cultivating mini cacti plants obtained by those housewives.
\end{abstract}

Keywords: mini cacti plants, cultivation, housewaves.

\footnotetext{
${ }^{1}$ Program Studi Agroekoteknologi, Fakultas Pertanian Universitas Udayana, rindangdwiyani@unud.ac.id

${ }^{2}$ Program Studi Agroekoteknologi, Fakultas Pertanian Universitas Udayana,

${ }^{3}$ Program Studi Agroekoteknologi, Fakultas Pertanian Universitas Udayana,

${ }^{4}$ Program Studi Agroekoteknologi, Fakultas Pertanian Universitas Udayana,
} 


\section{PENDAHULUAN}

Banjar Kerthabuana Kaja merupakan salah satu banjar dinas, sekaligus banjar adat yang merupakan bagian wilayah Desa Dangin Puri Kangin, Kecamatan Denpasar Utara. Salah satu kelompok yang ada di banjar tersebut adalah kelompok ibu-ibu PKK, yang anggotanya kebanyakan ibu rumah tangga Kegiatan rutin yang dilakukan oleh para ibu tersebut adalah arisan serta penimbangan rutin balita.

Di tengah meningkatnya kebutuhan hidup, tentunya waktu yang tersisa dapat dimanfaatkan oleh para ibu tersebut untuk membantu keluarga mendapatkan penghasilan. Salah satu cara yaitu dengan menjadi pemasok kaktus mini bagi pengusaha kaktus mini yang ada di lokasi yang sama. CV Karuna adalah salah satu pengusaha kaktus mini yang menjual produknya secara on line dan berlokasi di Banjar Kerthabuana Kaja. CV Karuna mengalami kesulitan untuk menyediakan kaktus dalam jumlah banyak. Diharapkan dengan meningkatnya keterampilan para ibu tersebut dalam budidaya kaktus, maka para ibu tersebut ke depannya dapat menjadi pemasok kaktus mini pada CV Karuna.

Kaktus mini merupakan tanaman yang sangat mudah dibudidayakan (Clemson, 2018), sehingga diharapkan para ibu PKK dengan cepat dapat menyerap ilmu budidaya kaktus dan dapat melakukan praktik secara langsung. Penelitian mengenai perbanyakan berbagai jenis kaktus sudah dilakukan terhadap berbagai jenis kaktus (Serrabo \& Da Silva, 2008) dan dapat dijadikan acuan dalam budidaya kaktus mini. Demikian pula cara budidaya kaktus mini dapat diunduh on line (omkicau.com, 2012), namun praktik budidaya diperlukan untuk meningkatkan keterampilan (skill).

Tujuan dari kegiatan ini adalah: Meningkatkan ketrampilan para ibu PKK dalam budidaya kaktus mini sehingga mereka dapat memanfaatkan waktu luang mereka dengan baik. 


\section{METODE PELAKSANAAN}

Metode yang digunakan dalam pelatihan ini adalah: (1) Ceramah yang akan diberikan oleh Dosen Fakultas Pertanian Unud serta narasumber dari CV Karuna; (2) Praktik budidaya, dimulai dari persiapan media untuk perbanyakan, perbanyakan kaktus mini hingga potting menjadi tanaman kaktus mini yang siap jual

\section{HASIL DAN PEMBAHASAN}

Diawali dengan ceramah yang dibawakan oleh narasumber dosen Fakultas Pertanian Universitas Udayana dan narasumber dari CV Karuna, pelatihan budidaya kaktus mini tersebut dilaksanakan di Banjar Kerthabuwana Kaja, Desa Dangin Puri Kangin, Kecamatan Denpasar Utara pada 16 Juli 2018.

Ibu-ibu PKK yang hadir pada acara pelatihan ini sangat antusias serta sangat serius dalam melakukan praktik budidaya. Hal ini ditunjukkan dengan banyaknya pertanyaan yang disampaikan kepada narasumber. Antusiasme ini menunjukkan bahwa bidang pertanian dicintai masyarakat. Meskipun peserta tidak meliki latar belakang pertanian, namun mereka menunjukkan keingintahuan yang besar mengenai budidaya kaktus ini. Satu minggu setelah praktik, para peserta datang kembali ke tempat melihat hasil praktiknya. Ini menunjukkan adanya minat yang besar dari peserta terhadap pelatihan yang dilaksanakan. Gambar 1-3 menunjukkan aktivitas pelatihan hingga hasil praktik yang dilihat satu minggu setelah pelatihan.

\section{KESIMPULAN DAN SARAN}

Dapat disimpulkan bahwa pelatihan budidaya kaktus mini bagi ibu-ibu PKK di Banjar Kertha Buwana Kaja, Denpasar Utara sudah berlangsung dengan sukses. Ibu-ibu mendapatkan ilmu serta skill dalam budidaya kaktus mini. Keberhasilan mereka dalam mengerjakan praktek menunjukkan bahwa adanya kesungguhan dari mereka untuk mengadopsi ilmu pertanian serta menunjukkan bahwa budidaya kaktus mini dapat dilakukan secara otodidak oleh siapapun yang berminat di bidang ini.

Disarankan bahwa ibu-ibu tersebut tetap dimotivasi serta hasil karyanya dalam produksi kaktus mini dapat ditampung oleh CV Karuna yang ada di lokasi.

\section{UCAPAN TERIMAKASIH}

Ucapan terimakasih disampaikan kepada Rektor Universitas Udayana beserta jajarannya; Ketua LPPM Universitas Udayana beserta staf yang sudah membiayai serta 
memfasilitasi proses pengabdian masyarakat ini dari sejak proposal hingga terlaksananya kegiatan.
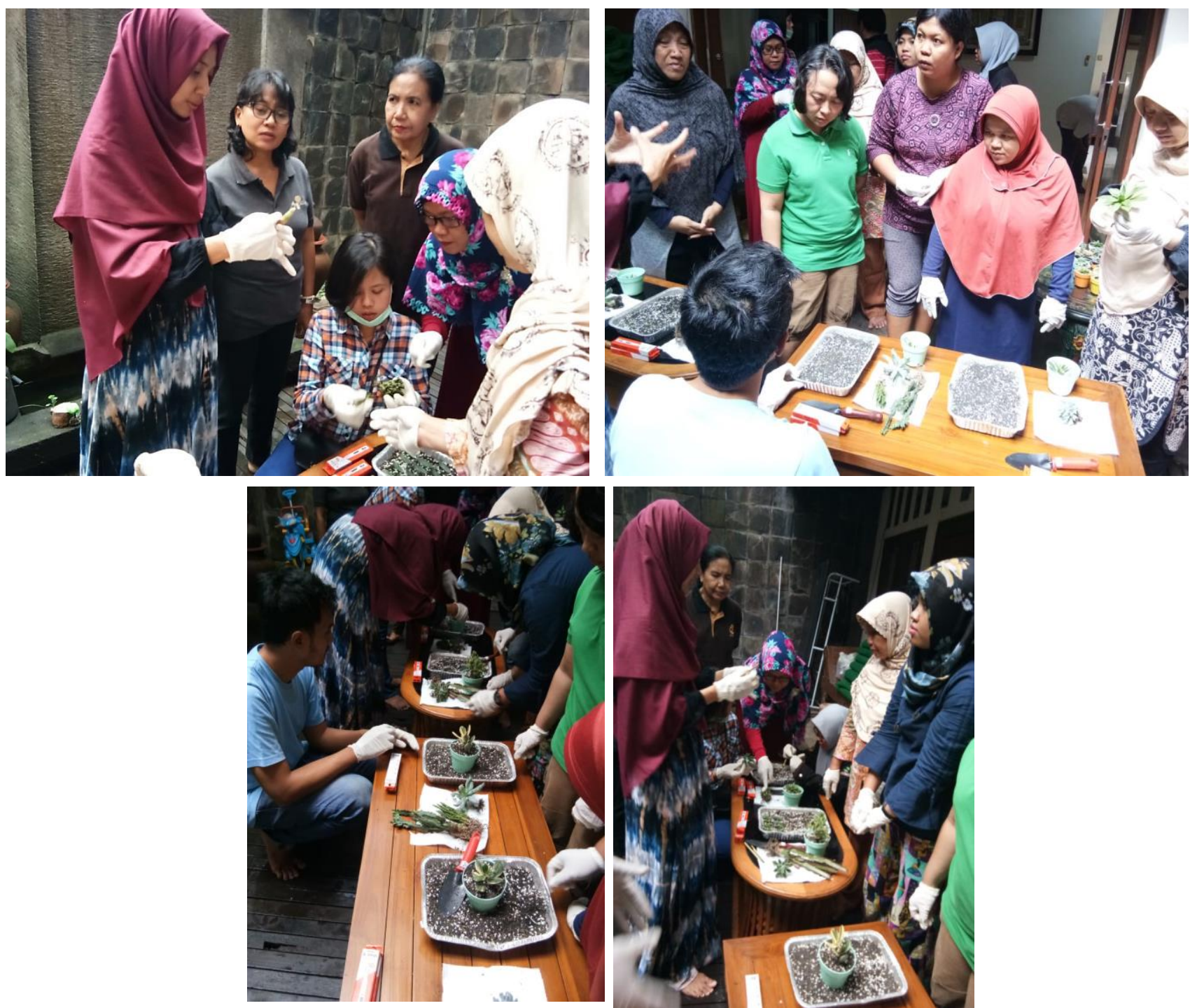

Gambar 1. Peserta pelatihan saat praktik dan mendengarkan penjelasan dari narasumber 

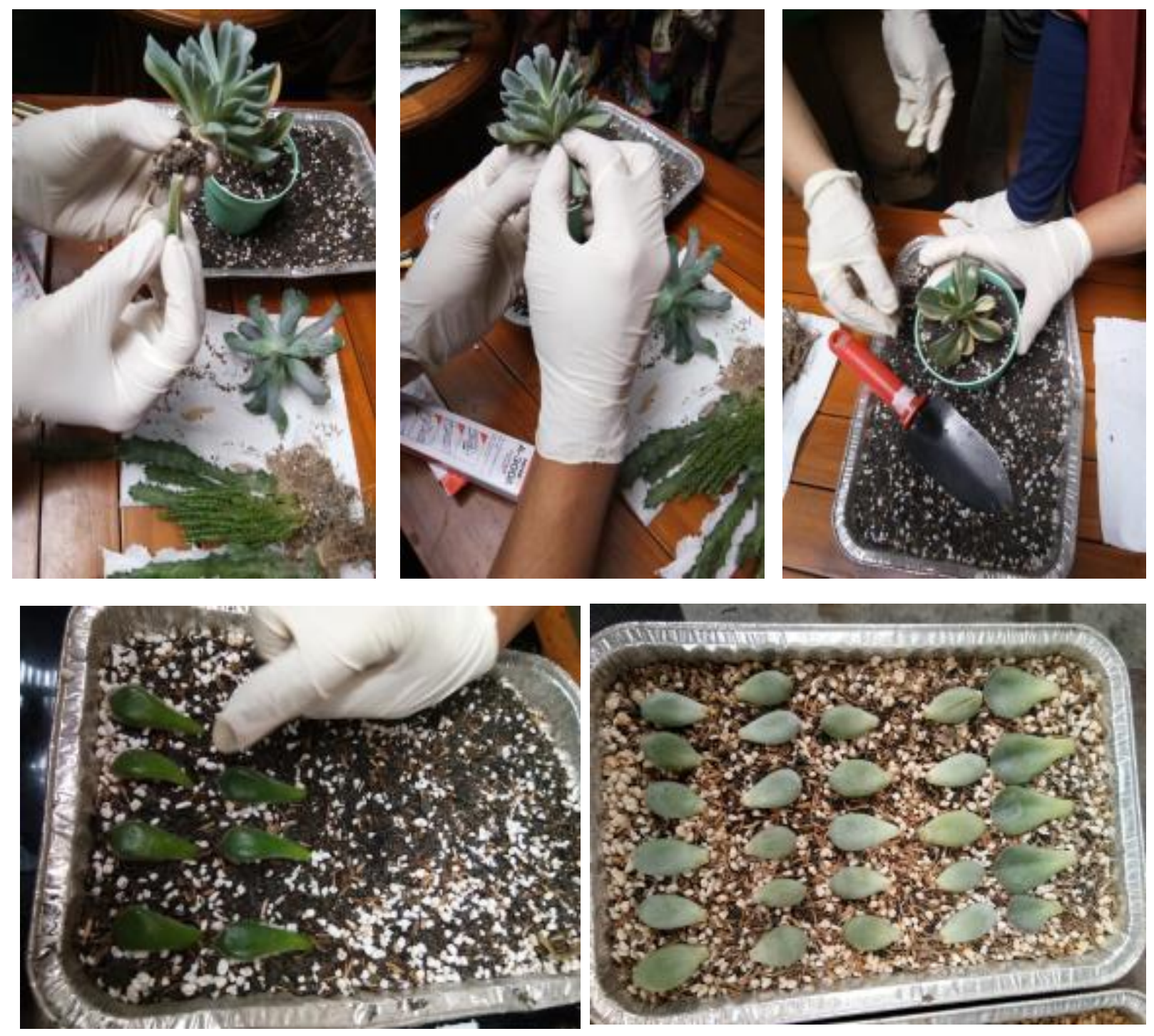

Gambar 2. Praktik perbanyakan dengan daun 

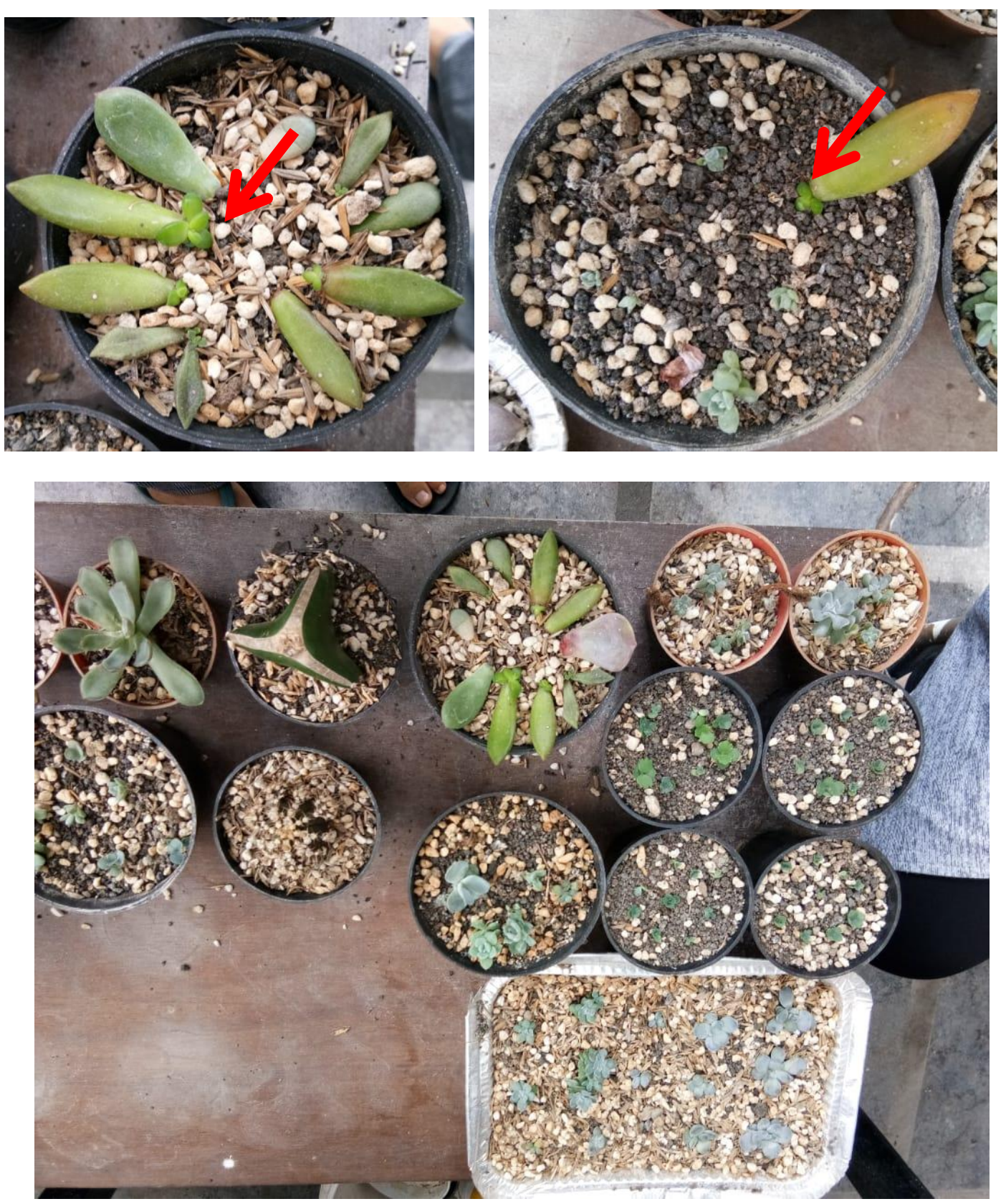

Gambar 3. Hasil praktek perbanyakan kaktus oleh peserta pada seminggu setelahnya; Tampak daun yang ditanam tumbuh tunas baru (panah), lama kelamaan daun awal akan layu dan digantikan oleh tanaman baru

\section{DAFTAR PUSTAKA}

Clemson. 2018.Home \& Garden Information Center. http:www.clemson.edu/Extension/hgic (download 18 Feb. 2018)

Omkicau.com. 2012. Kaktus Tumbuh Prima dan Cepat. https://omkicau.com/wpcontent/uploads/2012/01/kaktus-tumbuh-prima.pdf (download 18 Feb. 2018)

Serrano, CR and da Silva, JAT. 2015. Micropropagation of Cactus Plants (Cactaceae). Research gate. 